\title{
Unusual records of vultures in northern India from the last two decades.
}

\author{
Sachin Ranade ${ }^{I^{*}}$ and Vibhu Prakash ${ }^{2}$ \\ ${ }^{1}$ Vulture Conservation Breeding Center, Rani, 781 131, Assam, India \\ ${ }^{2}$ Vulture Conservation Breeding Center, Pinjore 134 102, Haryana, India \\ *Corresponding author: s.ranade@bnhs.org
}

http://dx.doi.org/10.4314/vulnew.v80i1.2

In recent decades populations of vultures across south Asia have declined substantially and their ranges have contracted concurrently (Naoroji 2006, Botha et al. 2017). We have monitored vultures during nationwide surveys, which are repeated every four years, and while working at the Vulture Conservation Breeding Centres in Haryana, West Bengal and Assam in India. In this article we present records of five vulture species that fall outside or at the edge of their current (reduced) distribution. We have provided the ages of the observed vultures, differentiated according to plumage characteristics, as well as the date and location of the observations.

\section{Indian Vulture (Gyps indicus):}

On 15 April 2002, an adult Indian Vulture (Figure 1) was seen near Siliguri, West Bengal (26 52'17.76"N, 88³1'57.72"E; location IV1 in Figure 2), with a small flock of vultures feeding on a cattle carcass next to the national highway, NH31. The flock consisted of three juvenile Himalayan Vultures (Gyps himalayensis), five White-rumped Vultures (Gyps bengalensis; two adult and three sub-adult), one adult Slender-billed Vulture (Gyps tenuirostris) and the adult Indian Vulture which was identified later from photographs (Figure 1). There were no other observations of Indian Vultures in eastern India during that road transect survey, or from Siliguri in later years.

On 21 September 2002, three juvenile Indian Vultures were seen at Badisher, Panchkula district,
Haryana $\left(30^{\circ} 42^{\prime} 29.52^{\prime \prime N}, 7^{\circ} 6^{\prime} 24.12 " \mathrm{E}\right.$; location IV2 in Figure 2). The birds were identified among a flock of 63 White-rumped Vultures and five juvenile Himalayan Vultures that were feeding on the carcass of a bull and perching on Chir Pines (Pinus roxburghii). Indian Vultures were seen during subsequent visits to the village in October 2003.

In 2004, following the confirmation that veterinary diclofenac was the primary cause of the widespread declines of vulture populations in Asia (Oaks et al. 2004), we carried out surveys in eleven districts of Haryana to determine local vulture population sizes. While surveying the Gurgaon district, on 30 April 2004, we came across three colonies of Indian Vultures near the village of Sohna (28 $16^{\prime} 14.52^{\prime \prime}$ N, 77²'45.48'E; location IV3 in Figure 2). The colonies were situated in the Aravali foothills, near two villages, Badoj and Kotla, adjoining the Jhir Forest. It was the first record of breeding Indian Vultures in Haryana. There were 14 nests on the cliff ledges, of which only two were active during the time of observation. The Indian Vulture had previously been recorded in Haryana's adjacent states, Rajasthan, Delhi and Uttar Pradesh (Vyas 1996, Ali \& Grubh 1984). Kalsi (1998) mentions the presence of Indian Vulture at Kalesar National Park, but there is a possibility of confusion with the Slenderbilled Vulture as they have only been considered separate species since 2001 (Rasmussen et al. 2001). The now-abandoned colony at Badoj was 
one of the northernmost records of Indian Vulture Pithauli village (27³8'17.16"N, 84 9'52.55"E) in in the Indian subcontinent and is at a similar latitude Chitwan National Park (Subedi \& Decandido to the first record of this species in Nepal, at 2013).

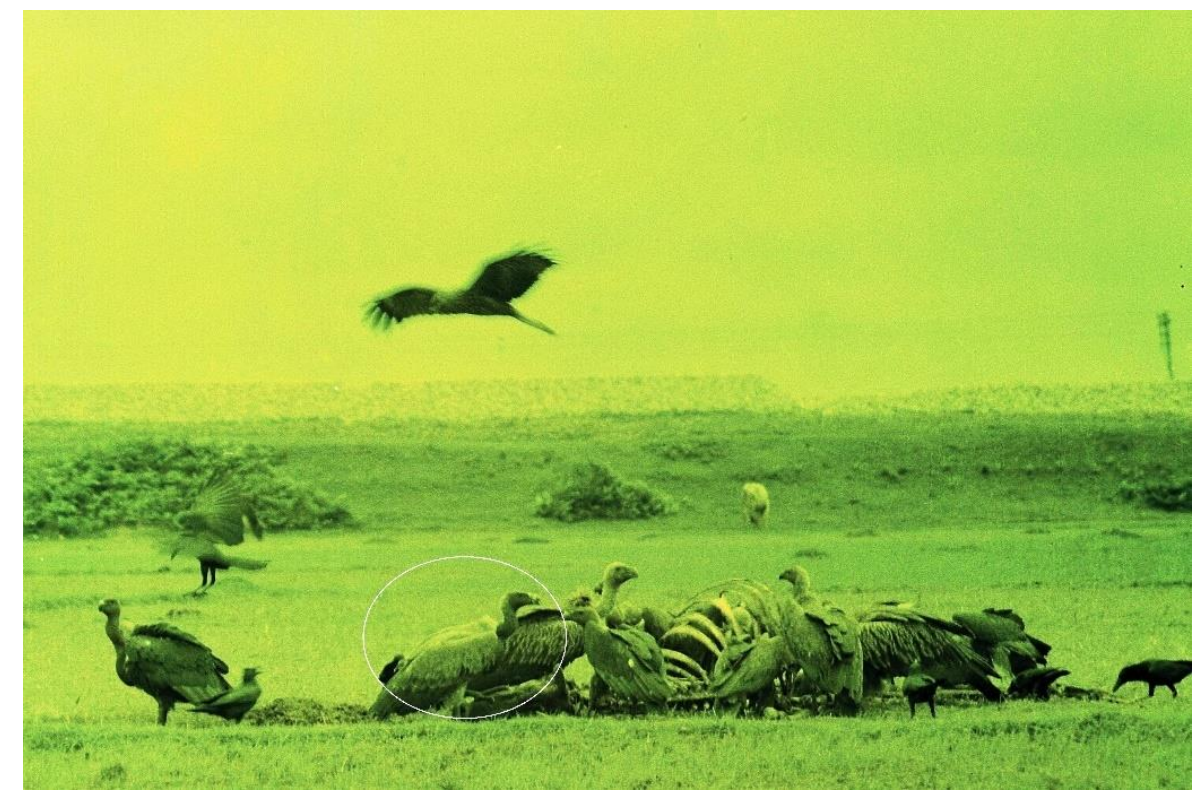

Figure 1: Photograph of an adult Indian Vulture near Siliguri, West Bengal, India on 15 April 2002 (corresponding to location IV1 in Figure 2). Photograph: Sachin Ranade.

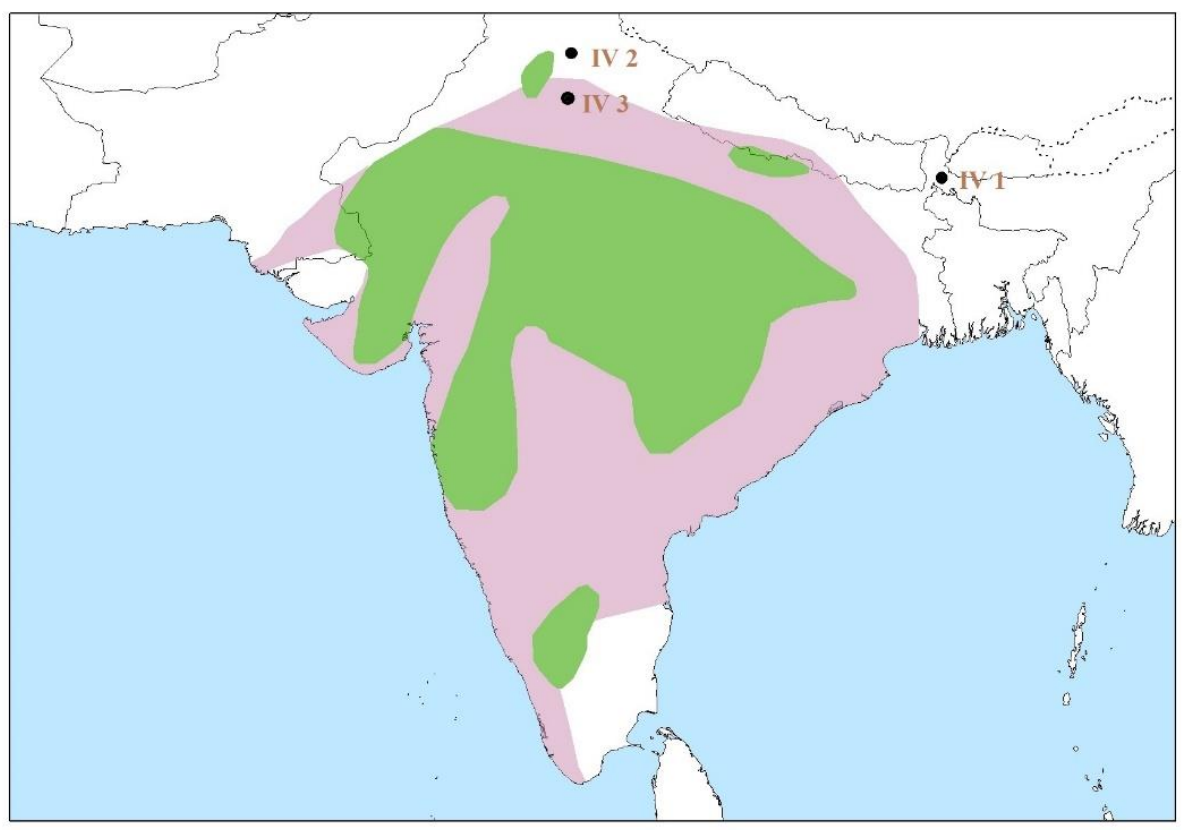

Figure 2: Distribution map for Indian Vulture with sighting locations corresponding to the text: one adult seen near Siliguri on 15 April 2002 (location IV1); three juveniles seen at Badisher in Panchkula on 21 September 2002 (location IV2); and three breeding colonies near Sohna, Gurgaon on 30 April 2004 (location IV3). The distribution map is adapted from Botha et al. (2017). Green shading indicates the current breeding range, pink shading indicates probable local extinction of the species. 


\section{Slender-billed vulture (Gyps tenuirostris):}

As the Slender-billed Vulture was only relatively recently recognized as a separate species to the Indian Vulture (Rasmussen et al. 2001), limited information is available about its historical distribution (Figure 3). Jones (1916) recorded Slender-billed Vulture (formerly as the subspecies Himalayan Long-billed Vulture) at Ambala, Haryana state, but there have been few records of Slender-billed Vultures from Haryana and Himachal Pradesh since then. On 11 January 2002, we observed two adult Slender-billed Vultures feeding with three adult White-rumped Vultures on a cattle carcass in a riverbed, on the outskirts of the Kalesar National Park (30³'29.4"N, $77^{\circ} 31^{\prime} 0.84^{\prime \prime E}$ ), Haryana state (location $\mathrm{SbV}$ in Figure 3). Two adult birds were also observed in flight at Badisher village, in Haryana (on the border with Himachal Pradesh) in October 2004. These observations were at the north-west limits of the historical distribution for the species (Figure 3).

\section{Griffon Vulture (Gyps fulvus):}

Griffon Vultures visit India in the winter period but are rarely observed in the northeast. On 27 February 2006, a subadult (second or third year) Griffon Vulture (Figure 4) was seen with a large flock of other Gyps vultures on the bank of the Kaljani River in Alipurduar $\left(26^{\circ} 28^{\prime} 47.28^{\prime \prime} \mathrm{N}\right.$, 89³0'57.96"E) in West Bengal, approximately 10 $\mathrm{km}$ from the Buxa Tiger Reserve. There were 15 White-rumped Vultures (mostly adults) and 80 immature Himalayan Vultures feeding on a cattle carcass close to the Kaljani Bridge (Figure 4). The subadult Griffon Vulture was identified by its rufous plumage and black cere (Duriez et al. 2011). Almost fifteen years later, on 1 January 2021, a juvenile Griffon Vulture was rescued by the Forest Department of West Bengal after it was found on the ground, exhausted, at Sukna, Darjeeling District (Figure 5). After rehabilitation, it was fitted with a Darvic leg ring and patagial tag and was released from Rajabhatkhawa in Buxa Tiger Reserve, Alipurduar $\left(26^{\circ} 36^{\prime} 55.8^{\prime \prime} \mathrm{N}, 8^{\circ} 33^{\prime} 38.88^{\prime \prime E}\right)$, on 19 February 2021. Griffon Vulture was the most abundant species encountered during raptor surveys in the Brahmputra Valley, Assam, in the early 1990s (Samant et al. 1995), but was not encountered during the vulture surveys carried out in the same areas during 2002, 2003, 2004, 2005, 2007, 2011 and 2015 (unpublished data), indicating a local decline in recent decades.

\section{Himalayan Vulture (Gyps himalayensis):}

The Himalayan Vulture was regarded as a "purely mountain bird" by Ali and Ripley (1983). However, the species is a well-documented winter visitor to the Northern Plains of India, with mostly juveniles and immature birds being migratory (Naoroji 2006). It has also been documented in peninsular India and Southeast Asia (Gilbert et al. 2006; Li \& Kasorndorkbua 2008; Praveen et al. 2014). On 25 April 2011, during national road transect surveys, we recorded two juvenile Himalayan Vultures at Miao, Changlang District of Arunachal Pradesh, and four juveniles on the Miao-Deban road in the Namdapha National Park (27³0'25.2"N, $\left.96^{\circ} 16^{\prime} 17.76^{\prime \prime} \mathrm{E}\right)$. These observations are from the extreme eastern part of India and the individuals could be part of the Sino-Himalayan breeding population. Although the area is within the broadscale wintering range of the Himalayan Vulture, there are very few records for the species there.

\section{Cinereous Vulture (Aegypius monachus):}

The Cinereous Vulture is a scarce and infrequent winter visitor to eastern India and is only an occasional visitor to Buxa Tiger Reserve, West Bengal (Allen et al. 1996), Dibru-Saikhowa National Park, Assam (Choudhury 2006), and Kaziranga National Park, Assam (Barua \& Sharma 1999). It has not been recorded in Nameri National Park, Assam (Barua \& Sharma 2005) and Rajiv Gandhi Orang National Park, Assam (Chakdar et 


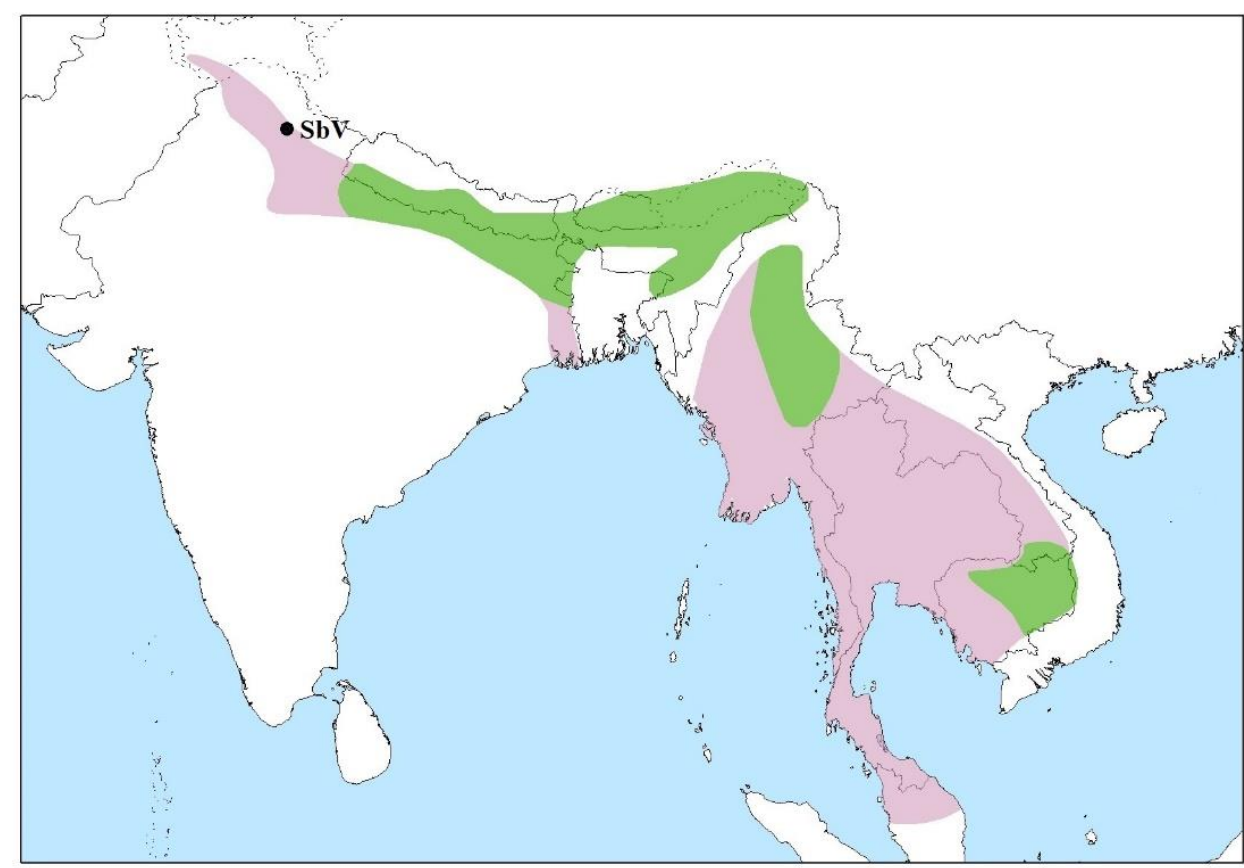

Figure 3: Distribution map for Slender-billed Vulture with sighting location corresponding to the text: two adults observed at Kalesar National Park on 11 January 2002 (location SbV). The distribution map is adapted from Botha et al. (2017). Green shading indicates the current breeding range, pink shading indicates probable local extinction of the species.

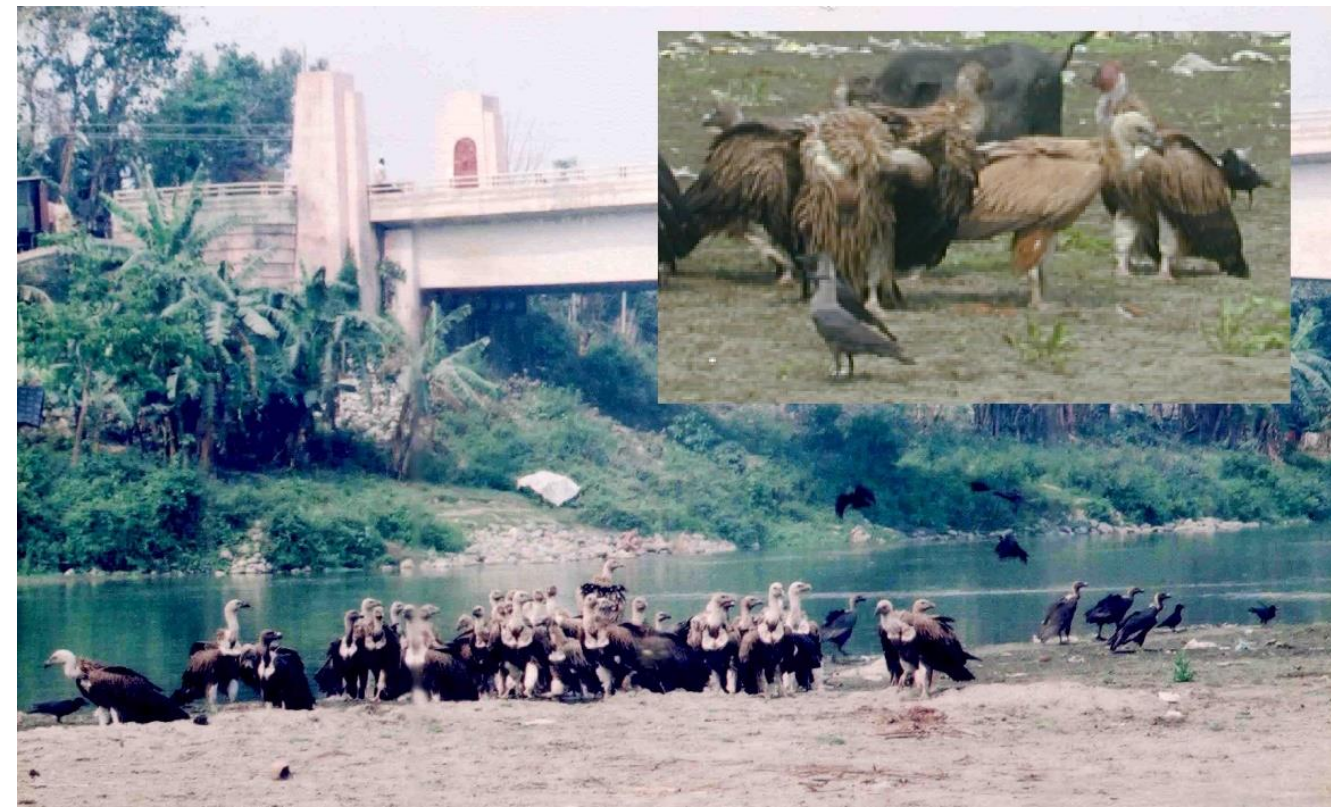

Figure 4: A flock of Himalayan Vultures and White-rumped Vultures at Alipurduar, West Bengal, India on 27 February 2006. The inset image shows a single Griffon Vulture among the Himalayan Vultures.

Photograph: Sachin Ranade. 
al. 2019). In 2002, a subadult Cinereous Vulture was found grounded and rescued and then kept at the Assam State Zoo and Botanical Garden, Guwahati, as it was deemed to be non-releasable. One juvenile individual was also observed on 4 May 2003 at Ajukha village $\left(27^{\circ} 44^{\prime} 22.92 " \mathrm{~N}\right.$, 95²8'24.96"E), Dibru-Saikhowa National Park, Tinsukia district. On 8 January 2009, a subadult Cinereous Vulture was seen with a flock of Himalayan Vultures and White-rumped Vultures at Sonakhali, Jalpaiguri district, West Bengal

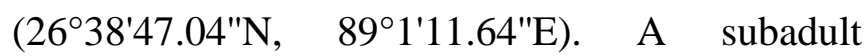
Cinereous Vulture was observed on 24 April 2015 at Baguri Range in Kaziranga National Park, Nagaon District (26³4'54.84"N, 93¹7'11.76"E), and another immature (second year) individual was rescued by the Forest Department and our team, following a poisoning incident on 29 February 2016 in Kamrup District. After its recovery, the vulture was ringed and released on 16 May 2016, at Rani $\quad\left(26^{\circ} 0^{\prime} 2.88^{\prime \prime} \mathrm{N}, \quad 91^{\circ} 32^{\prime} 26.52^{\prime \prime E}\right), \quad$ Kamrup District. On 25 December 2019, a juvenile Cinereous Vulture, along with three Himalayan Vultures, was attracted to the pre-release aviary $\left(26^{\circ} 36^{\prime} 55.8^{\prime \prime} \mathrm{N}, 8^{\circ} 33^{\prime} 38.88^{\prime \prime} \mathrm{E}\right)$ of the vulture reintroduction program at Buxa Tiger Reserve. More recently, between 1 and 10 December 2020, a juvenile Cinereous Vulture spent ten days near the Vulture Conservation Breeding Center, Rani $\left(26^{\circ} 0^{\prime} 2.88^{\prime \prime} \mathrm{N}, 91^{\circ} 32^{\prime 2} 26.52^{\prime \prime E}\right.$; Figure 6).

\section{Discussion}

Vultures often travel long distances in search of food and immatures may traverse very large ranges before they reach breeding age (Mundy et al. 1992). Hence, it is difficult to accurately delineate the full extent of their distribution ranges. Out of the five species observed and documented here, two are listed as Critically Endangered (Indian and Slenderbilled Vultures), two as Near Threatened (Himalayan and Cinereous Vultures), and one as
Least Concern (Griffon Vulture), and all have exhibited population declines and range contractions in India in recent decades (MoEFCC 2020, IUCN 2021). Therefore, it is essential to record their presence as thoroughly as possible to inform further monitoring and conservation measures (Botha et al. 2017). For example, records of vulture feeding, roosting and nesting sites, as well as the locations of mortality incidents, provide important information for conservation planning. Our observations provide additional information about the distribution of vultures in northern and eastern regions of India.

The observations of Indian and Slender-billed Vultures, especially those of adults outside the currently recognized distribution range, suggests either a wider distribution than previously thought, exploratory movements to new areas, or better detection due to increased survey efforts. The observations of immature Himalayan Vultures, Griffon Vultures and Cinereous Vultures in the plains of northeast India during the winter period confirm the tendency of immature vultures to range widely (Garcia-Ripolles et al. 2011, Castaño et al. 2015). It is during this wandering period that vultures are most likely to encounter a wide range of potentially fatal threats (Efrat et al. 2020), and so it is useful to document their occurrence throughout all life stages so that those threats (or important sites or resources) can be identified and recorded. We encourage accurate documentation and publication of unusual observations of vultures, including details about their numbers, ages, behaviours and locations, in order to inform future monitoring and conservation measures. In the case of the Himalayan Vulture, the individuals visiting the easternmost areas of India could originate from the Sino-Himalayan population. We feel that more efforts are required to survey and report the distribution and movements of these species in northeast India, perhaps including marking and telemetry studies. 


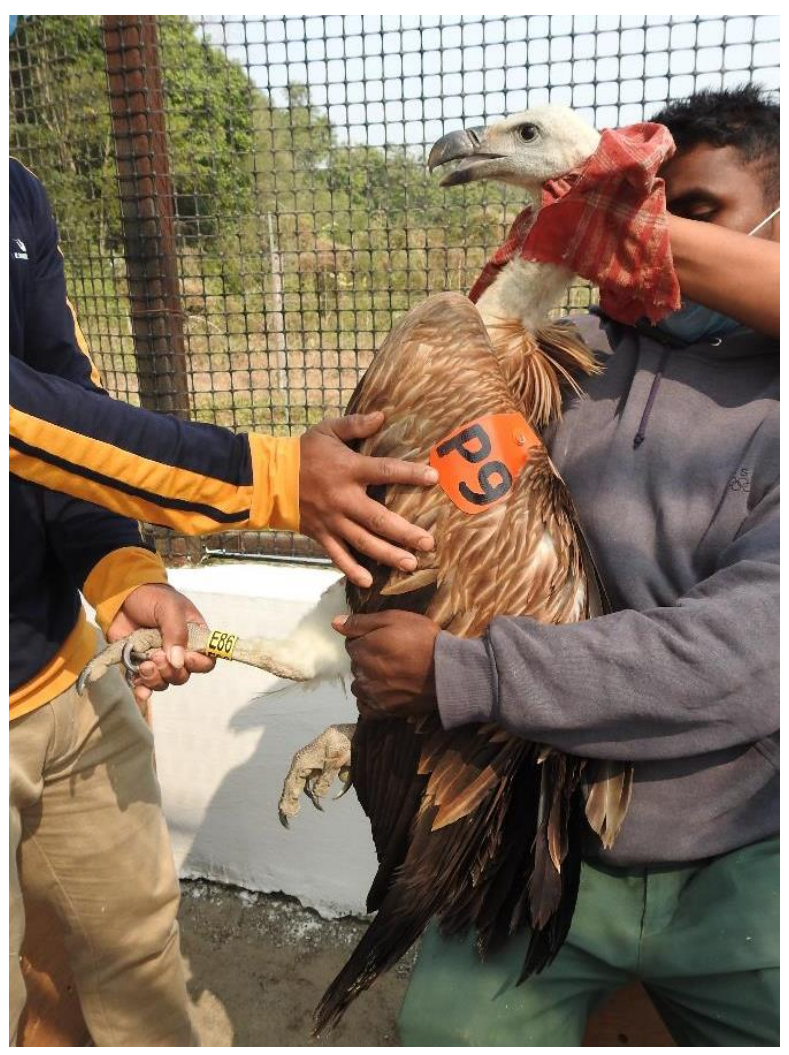

Figure 5: Photograph of a juvenile Griffon Vulture that was found grounded due to exhaustion on 1 January 2021, at Sukna, Darjeeling district, West Bengal. It was rehabilitated and released at the Buxa Tiger Reserve on 19 February 2021. Photograph: Sachin Ranade.

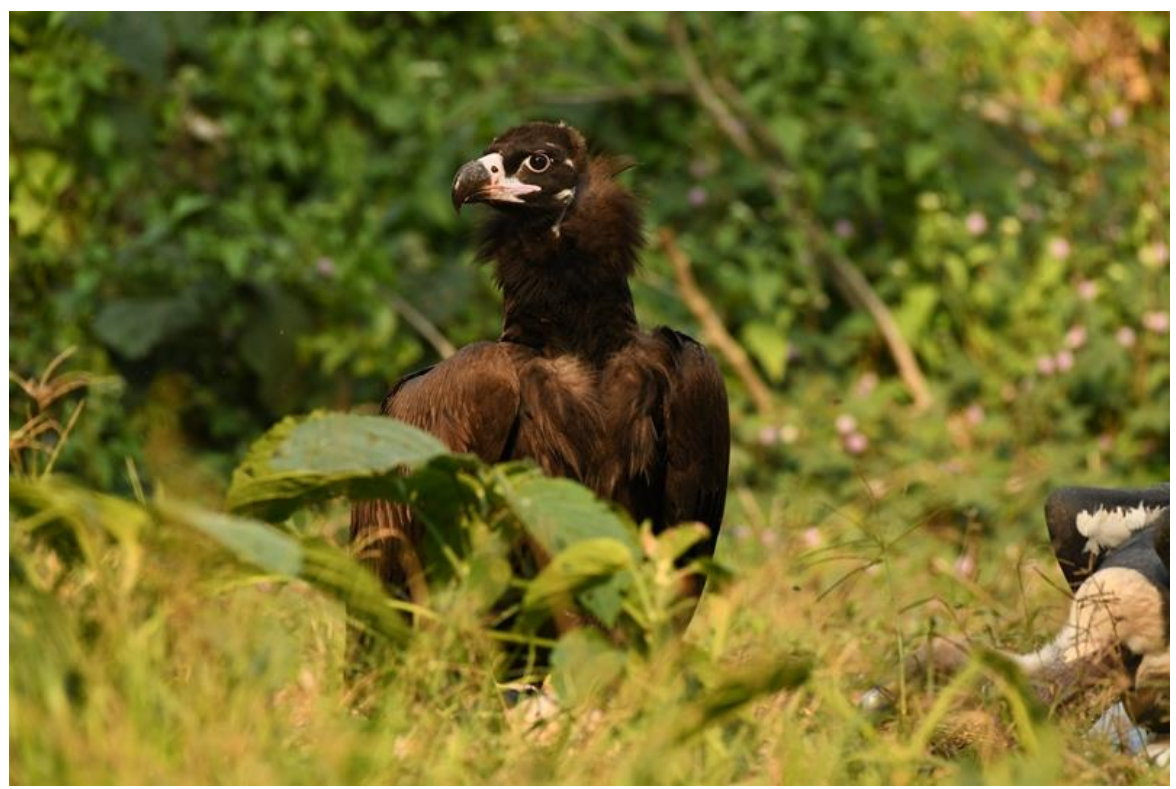

Figure 6: Photograph of a juvenile Cinereous Vulture that was observed from 1 to 10 December 2020 at Rani, Assam, India. Photograph: Sachin Ranade. 


\section{Acknowledgements}

The study was conducted as part of the BNHS Vulture project, funded by the Darwin Initiative, UK, and Royal Society for the Protection of Birds, UK. The authors would like to thank the Forest Departments of Haryana, West Bengal and Assam for kindly permitting us to carry out the surveys and establish Vulture Conservation Breeding Centers in respective states. We acknowledge the Forest Departments of Himachal Pradesh and Arunachal Pradesh for the permissions to carry out vulture surveys. We would like to thank Mr S Sarvanan for participating in the vulture survey in Haryana in 2004 and Ms Sofi Hinchliffe, Convention on Migratory Species Office, Abu Dhabi, for kindly sharing the distribution maps.

\section{References}

Ali, S., \& Ripley, S.D. 1983. Handbook of the birds of India and Pakistan together with those of Bangladesh, Nepal, Bhutan and Sri Lanka. Compact edition. Oxford University Press, Delhi.

Ali, S. \& Grubh, R.B. 1984. Ecological study of bird hazards at Indian aerodromes. Phase II First Annual Report. Bombay Natural History Society, Mumbai.

Allen, D., Anderton, J. \& Kazmeirczak, K. 1996. Report on an ornithological visit to Buxa Tiger Reserve, West Bengal, India 17 February to 6 March 1992. Forktail 12: 31-48.

Barua, M. \& Sharma, P. 1999. Birds of Kaziranga National Park, India. Forktail 15: 47-60.

Barua, M. \& Sharma, P. 2005. The birds of Nameri National Park, Assam, India. Forktail 21: 15-26.

Botha, A. J., Andevski, J., Bowden, C. G. R., Gudka, M., Safford, R. J., Tavares, J. \& Williams, N. P. 2017. Multi-species Action Plan to Conserve African-Eurasian Vultures. CMS Raptors MOU Technical Publication No. 5. CMS Technical Series No. 35. Coordinating Unit of the CMS Raptors MOU, Abu Dhabi, United Arab Emirates.

Castaño J. P., Sánchez J. F., Díaz-Portero M. A. \& Robles, M. 2015. Dispersal and survival of juvenile black vultures Aegypius monachus in Central Spain. Ardeola 62: 351-361.

Chakdar, B., Singha, H., \& Choudhury, M. R. 2019. Bird community of Rajiv Gandhi Orang National Park, Assam. Journal of Asia-Pacific Biodiversity 12: 498-507.

Choudhury, A. 2006. Birds of Dibru-Saikhowa National Park and Biosphere Reserve, Assam, India. Indian Birds 2: 95-105.

Duriez, O., Eliotout, B. \& Sarrazin, F. 2011. Age identification of Eurasian Griffon Vultures Gyps fulvus in the field. Ringing and Migration 26: 24-30.

Efrat, R., Hatzofe, O., Miller, Y. \& Berger-Tal, O. 2020. Determinants of survival in captive-bred Griffon Vultures Gyps fulvus after their release to the wild. Conservation Science and Practice 2020; 2:e308.

Ferguson-Lees, J. \& Christie, D. A. 2001. Raptors of the World. Princeton University Press, Princeton.

Garcia-Ripolles, C., Lopez-Lopez, P. \& Urios, V. 2011. Ranging behaviour of non-breeding Eurasian Griffon Vultures Gyps fulvus: a GPS-telemetry study. Acta Ornithologica 46: 127-134. 
Gilbert, M., Chansocheat, S. \& Sureda, N. 2006. First record of Himalayan Griffon vulture Gyps himalyensis in Chhep, Preah Vihear, northern Cambodia. Vulture News 55: 4-5.

IUCN 2021. The IUCN Red List of Threatened Species. Version 2021-1. https://www.iucnredlist.org. Downloaded on 31/05/2021.

Jones, A. E. 1916 Gyps tenuirostris (Hodgson), the Himalayan Long-billed vulture, breeding near Ambala, Punjab. Journal of the Bombay Natural History Society 24: 358.

Kalsi, R. S. 1998. Birds of Kalesar Wildlife Sanctuary, Haryana, India. Forktail 13: 29-32.

Li, Y. D \& Kasorndorkbua, C. 2008. The status of the Himalayan Griffon Gyps himalayensis in SouthEast Asia. Forktail 24: 57-62.

MoEFCC 2020. Action Plan for Vulture Conservation in India, 2020-2025 Ministry of Environment, Forest and Climate Change Government of India.

Mundy, P., Butchart, D., Ledger, J. \& Piper, S. 1992. The vultures of Africa. Acorn Books and Russel Friedman Books: Randburg and Halfway House, South Africa.

Naoroji, R. 2006. Birds of Prey of the Indian Subcontinent. Christopher Helm, A \& C Black Publishers Ltd., London.

Oaks, J. L., M. Gilbert, M. Z. Virani, R. T. Watson, C. U. Meteyer, B. A. Rideout, H. L. Shivaprasad, S. Ahmed, M. J. I. Chaudhry, M. Arshad, S. Mahmood, A. Ali \& Khan, A.A. 2004. Diclofenac residues as the cause of vulture population decline in Pakistan. Nature 427: 630-33.

Praveen, J., Nameer, P.O., Karuthedathu, D., Ramaiah, C., Balakrishnan, B., Rao, K. M., Shurpali, S., Puttaswamaiah, R. \& Tavcar, I. 2014. On the vagrancy of the Himalayan Vulture Gyps himalayensis to southern India. Indian BIRDS 9: 19-22.

Rasmussen, P. C., Clark, W. S., Parry, S. J. \& Schmitt, J. 2001. Field identification of 'Long-billed Vultures (Indian and Slender-billed Vultures). Oriental Bird Club Bulletin 34: 24-29.

Samant, J.S., Prakash, V. \& Naoroji, R. 1995. Ecology and behaviour of resident raptors with special reference to endangered species. Final Report to the US Fish and Wildlife Service Grant number 141600009-90-1257. Bombay Natural History Society, Mumbai.

Subedi, T. R. \& Dcandido, R. 2013. Indian Vulture Gyps indicus: first record for Nepal. Birding Asia 19: 115-116.

Vyas, S. 1996. Checklist of the birds of the Delhi region: an update. Journal of the Bombay Natural History Society 93: 219-237. 